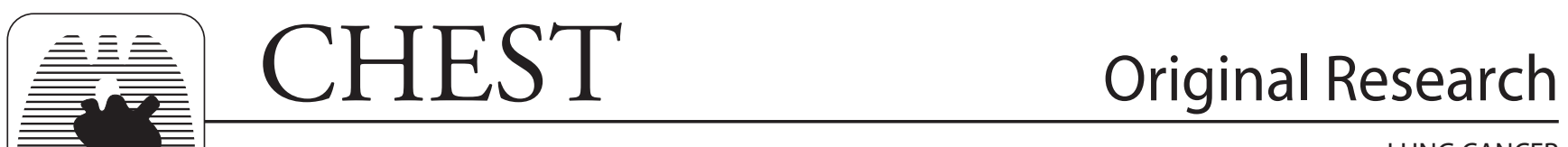

LUNG CANCER

\title{
Assessing the Relationship Between Lung Cancer Risk and Emphysema Detected on Low-Dose CT of the Chest*
}

\author{
Juan P. de Torres, MD; Gorka Bastarrika, MD; Juan P. Wisnivesky, MD, MPH; \\ Ana B. Alcaide, MD; Arantza Campo, MD; Luis M. Seijo, MD; \\ Jesús C. Pueyo, MD; Alberto Villanueva, MD; María D. Lozano, MD; \\ Usua Montes, RN; Luis Montuenga, PhD; and Javier J. Zulueta, MD, FCCP
}

Rationale: Identification of risk factors for lung cancer can help in selecting patients who may benefit the most from smoking cessation interventions, early detection, or chemoprevention. Objective: To evaluate whether the presence of emphysema on low-radiation-dose CT (LDCT) of the chest is an independent risk factor for lung cancer.

Methods: The study used data from a prospective cohort of 1,166 former and current smokers participating in a lung cancer screening study. All individuals underwent a baseline LDCT and spirometry followed by yearly repeat LDCT studies. The incidence density of lung cancer among patients with and without emphysema on LDCT was estimated. Stratified and multiple regression analyses were used to assess whether emphysema is an independent risk factor for lung cancer after adjusting for age, gender, smoking history, and the presence of airway obstruction on spirometry.

Results: On univariate analysis, the incidence density of lung cancer among individuals with and without emphysema on LDCT was 25.0 per 1,000 person-years and 7.5 per 1,000 person-years, respectively (risk ratio $[\mathrm{RR}], 3.33$; 95\% confidence interval $[\mathrm{CI}], 1.41$ to 7.85 ). Emphysema was also associated with increased risk of lung cancer when the analysis was limited to individuals without airway obstruction on spirometry $(\mathrm{RR}, 4.33 ; 95 \% \mathrm{CI}, 1.04$ to 18.16). Multivariate analysis showed that the presence of emphysema (RR, 2.51; 95\% CI, 1.01 to 6.23) on LDCT but not airway obstruction (RR, $2.10 ; 95 \%$ CI, 0.79 to 5.58 ) was associated with increased risk of lung cancer after adjusting for potential cofounders.

Conclusions: Results suggest that the presence of emphysema on LDCT is an independent risk factor for lung cancer.

(CHEST 2007; 132:1932-1938)

Key words: airway obstruction; CT; emphysema; lung cancer; risk factors

Abbreviations: $\mathrm{CI}=$ confidence interval; $\mathrm{IQR}=$ interquartile range; $\mathrm{LDCT}=$ low-radiation-dose $\mathrm{CT}$; $\mathrm{RR}=$ risk ratio

$\mathbf{L}$ ung cancer is the deadliest malignancy in the world among men and women. ${ }^{1,2}$ Major public health efforts have focused on developing new interventions to decrease smoking rates, the main risk factor for lung cancer, and to test for strategies that could lead to early detection or effective chemoprevention. In particular, lung cancer screening using low-radiation-dose CT (LDCT) is a promising strategy currently undergoing intensive research efforts. An important aspect of these strategies is the ability to identify patients at high risk for lung cancer who may benefit the most from smoking cessation treatments, early diagnosis, or chemoprevention. Moreover, several studies ${ }^{3}$ have shown that the cost-effectiveness of these interventions is highly dependent on the prevalence of lung cancer in the target population.

COPD, also strongly associated with cigarette smoking, is a highly prevalent condition that in industrialized countries is only second to heart disease as a cause of death. ${ }^{3}$ Most patients with COPD have a combination of chronic bronchitis and emphysema, which is anatomically defined as an abnormal permanent enlargement of the airspaces distal to 
the terminal bronchioles, accompanied by destruction of their walls without obvious fibrosis. ${ }^{4}$ According to international guidelines, the diagnosis of COPD requires the presence of airway obstruction on spirometry. ${ }^{5}$ In recent years, CT has been shown to accurately identify areas of the lung parenchyma involved with emphysema.5,6 CT may be more sensitive than pulmonary function tests for the detection of emphysema, but the clinical significance of emphysema diagnosed on CT in the absence of airway obstruction is not yet clear.

It has been shown that patients with COPD, defined by the presence of airway obstruction, are at increased risk for lung cancer. ${ }^{7}$ However, there are limited data regarding the potential association between emphysema diagnosed on chest CT and lung cancer, particularly among individuals with normal airway function. In this study, we used data from an unselected population of current and former smokers participating in a lung cancer screening study to assess whether emphysema detected on LDCT is an independent risk factor for lung cancer.

\section{Materials AND Methods}

The study was conducted using data from a prospective cohort of individuals enrolled in a lung cancer screening study using LDCT from September 2000 to December 2005.8 Eligibility criteria included age $\geq 40$ years, $>10$ pack-year smoking history, and no symptoms of lung cancer. The study protocol consisted of a baseline LDCT of the chest followed by annual repeat studies for up to 5 years. All patients underwent spirometry at enrollment and a baseline standardized questionnaire to collect sociodemographic information and smoking history data. The ethics committee of the University of Navarra approved the study protocol, and all subjects signed an informed consent form prior to participation.

*From the Departments of Respiratory Diseases (Drs. de Torres, Alcaide, Campo, Seijo, and Zulueta), Radiology (Drs. Bastarrika, Pueyo, and Villanueva), and Pathology (Dr. Lozano), University Clinic of Navarra, University of Navarra, Navarra, Spain; Division of Pulmonary and Critical Care Medicine, Mount Sinai School of Medicine (Dr. Wisnivesky), New York, NY; and Centre for Applied Medical Research-CIMA (Ms. Montes and Dr. Montuenga), University of Navarra, Navarra, Spain.

The study was approved by the Ethics Committee of the University Clinic of Navarra.

This work was funded in part by the Spanish Ministry of Health (FIS project PI04/2404) and the Department of Health of the Government of Navarra.

The authors have no conflicts of interest to disclose.

Manuscript received June 13, 2007; revision accepted August 14, 2007.

Reproduction of this article is prohibited without written permission from the American College of Chest Physicians (www.chestjournal. org/misc/reprints.shtml).

Correspondence to: Javier I. Zulueta, MD, FCCP, Department of Respiratory Diseases, Clínica Universitaria de Navarra, Avda. Pio XII, 36, 31008 Pamplona, Spain; e-mail: jzulueta@unav.es

DOI: 10.1378/chest.07-1490

\section{LDCT}

LDCT examinations were performed in a single breath-hold at end-inspiration. The initial 297 subjects were studied with a single-slice helical scanner (Somatom Plus 4; Siemens; Erlangen, Germany) at low-dose settings (140 kilovolt peak, $43 \mathrm{~mA}$ seconds) and 1.5 pitch with a collimation of $8 \mathrm{~mm}$. We used a four-row multislice helical CT scanner (Somatom Volume Zoom; Siemens; Forchheim, Germany) also at a low-dose setting (120 kilovolt peak, $20 \mathrm{~mA}$ seconds, and 1.25-mm slice thickness) for all subsequent studies. All images were reconstructed using a highspatial-frequency algorithm and displayed at window settings appropriate for viewing the lung parenchyma (window width of 1,500 Hounsfield units, and window center of -650 Hounsfield units). ${ }^{9}$

Assessment of Emphysema on LDCT

All images were read by two expert chest radiologists for visual assessment of the presence of emphysema, using validated criteria. ${ }^{6}$ In brief, the extent of emphysema was graded from 0 to 4, with a grade of 0 indicating no emphysema, and a grade of 4 indicating the presence of emphysema in $>75 \%$ of the lung. ${ }^{6}$ For the purpose of this study, patients with a score $\geq 1$ were classified as having emphysema.

\section{Spirometry}

Airway function was measured at baseline in all study participants using a flow spirometer ( $\operatorname{V} \max 22$; SensorMedics; Yorba Linda, CA) according to the standards of the American Thoracic Society. ${ }^{4} \mathrm{FEV}_{1}$ and FVC measures were expressed as a percentage of the predicted value according to the European Community Lung Health Survey. ${ }^{10}$ Using the criteria established by the Global Initiative for Chronic Obstructive Lung Disease, subjects with a $\mathrm{FEV}_{1} / \mathrm{FVC}$ ratio $<70 \%$ were classified as having airway obstruction. ${ }^{5}$

\section{Lung Cancer Diagnostic Algorithm}

Study participants were evaluated for the presence of lung cancer using a standardized diagnostic algorithm. ${ }^{11}$ Briefly, patients with noncalcified nodules $<10 \mathrm{~mm}$ were followed up with repeat LDCTs and further workup if growth of a nodule was detected. Subjects with suspicious nodules $\geq 10 \mathrm{~mm}$ were immediately referred for positron emission tomography, percutaneous needle biopsy, or intraoperative biopsy. For the purpose of the study, all cases of lung cancer diagnosed as a consequence of screening or due to a new onset of symptoms (interval cases) were included in the analysis.

\section{Data Analysis}

Normal data are presented as mean $\pm \mathrm{SD}$, and nonnormal variables are presented as median (interquartile range [IQR]). The agreement between raters for the visual assessment of emphysema and the $\kappa$ coefficient for interrater reliability was calculated. ${ }^{12,13}$

The incidence density of lung cancer was calculated with person-years as the denominator under the Poisson assumption. ${ }^{14}$ We used the risk ratio (RR) with $95 \%$ confidence intervals (CIs) to compare the risk of lung cancer among study subjects with and without emphysema.

Stratified analyses were also conducted to evaluate the relationship between emphysema and lung cancer risk among patients with normal airway function. We used Poisson regression 
Table 1-Baseline Characteristics of Study Participants*

\begin{tabular}{lc}
\hline \hline \multicolumn{1}{c}{ Characteristics } & Data \\
\hline Age, yr & $54 \pm 8$ \\
Male gender, \% & 74 \\
Smoking history, median pack-yr & 33 (IQR: 22) \\
Spirometry results, \% predicted & $95 \pm 18$ \\
FEV $_{1}$ & $105 \pm 16$ \\
FVC & $75 \pm 8$ \\
FEV & FVC ratio \\
Airway obstruction, \%† & 25 \\
LDCT result & \\
Emphysema, \%+ & 29 \\
\hline
\end{tabular}

*Data are presented as mean $\pm \mathrm{SD}$ unless otherwise indicated. †Percentage of participants with $\mathrm{FEV}_{1} / \mathrm{FVC}<70 \%$ of predicted. ${ }_{+}$Percentage of participants with emphysema on LDCT grade 1 or more.

to assess whether emphysema on LDCT was independently associated with lung cancer incidence density after controlling for other known risk factors such as age, gender, presence of airway obstruction, and smoking history (number of pack-years). All analyses were performed with statistical software (version 9.0; SAS Institute; Cary, NC) and using two-sided p values.

\section{RESUlts}

A total of 1,166 individuals were included in the study. Baseline characteristics of the study participants are shown in Table 1. All participants were white western Europeans, mean age was $54 \pm 8$ years, and $74 \%$ were male. The median number of pack-years smoked was 33 (IQR: 22 pack-years). Overall, 29\% (95\% CI, 26 to $31 \%$ ) of the subjects had emphysema on baseline LDCT and 25\% (95\% CI, 22 to 27\%) had airway obstruction on spirometry (Fig 1). Fifty-three percent of the participants with emphysema on CT had no airway obstruction. The interrater agreement for the presence or absence of emphysema based on visual assessment was excellent $(\kappa$ coefficient $=0.91$ ).

Lung cancer was diagnosed in 23 participants. Seventeen cases were detected on baseline screening, and 6 cases were detected on annual repeat screening. No interval lung cancers were diagnosed. Adenocarcinoma was the most frequent histologic type $(57 \%)$, followed by squamous cell carcinoma $(22 \%)$, small cell carcinoma (17\%), and large cell carcinoma (4\%). Nearly $80 \%$ of the cancers were diagnosed in stage I, $13 \%$ in stage II, and $7 \%$ in stage III.

\section{Relationship Between Emphysema Distribution, Cancer Location, and Histologic Type}

Of the 17 individuals with lung cancer and emphysema on LDCT, 16 patients (94\%) had heterogenous emphysema with upper-lobe predominance and the cancer was located in the upper lobes. One individual had homogenous emphysema and lung cancer in the left lower lobe. The histologic type of cancer in 10 of the 17 individuals with emphysema (58\%) was adenocarcinoma.

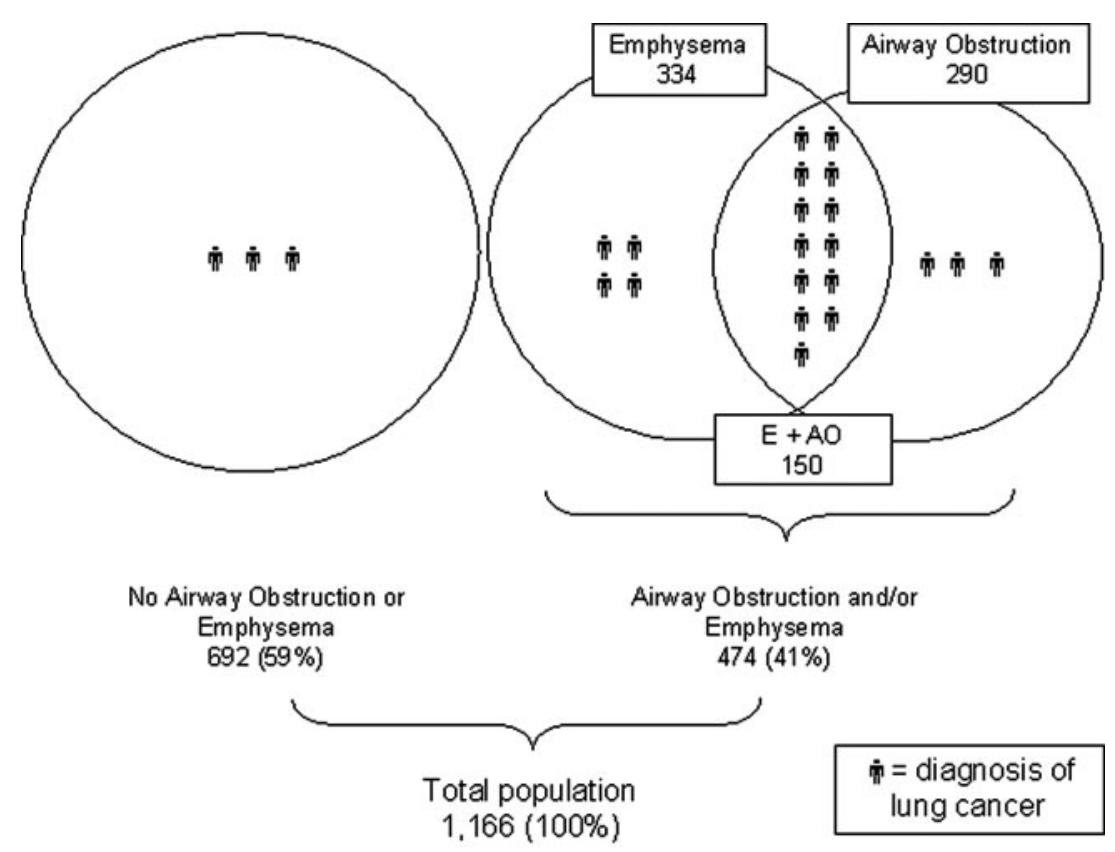

FIGURE 1. Distribution of participants with lung cancer according to the presence or absence of airway obstruction (AO) and/or emphysema (E). 
Table 2-Unadjusted and Stratified Association Between Emphysema, Airway Obstruction, and Incidence of Lung Cancer

\begin{tabular}{lcccc}
\hline \hline \multicolumn{1}{c}{ Risk Factors } & $\begin{array}{c}\text { No. of Lung } \\
\text { Cancers }\end{array}$ & $\begin{array}{c}\text { Person-Years } \\
\text { of Follow-up }\end{array}$ & $\begin{array}{c}\text { Incidence Density } \\
\text { (per 1,000 Person-Years) }\end{array}$ & RR (95\% CI) \\
\hline Univariate analysis & & & & \\
$\quad$ No emphysema & 8 & 1,065 & 7.5 & Reference \\
$\quad$ Emphysema & 15 & 600 & 25.0 & $3.33(1.41-7.85)$ \\
$\quad$ No airway obstruction & 8 & 1,200 & 6.7 & $4.83(2.05-11.41)$ \\
$\quad$ Airway obstruction & 15 & 465 & 32.3 & Reference \\
$\quad$ No emphysema, no airway obstruction & 3 & 876 & 3.4 & $5.50(1.51-19.99)$ \\
$\quad$ Emphysema or airway obstruction & 10 & 531 & 18.8 & $10.94(3.01-39.74)$ \\
$\quad$ Emphysema and airway obstruction & 10 & 267 & & \\
Stratified analysis & & & 3.5 & Reference \\
$\quad$ No airway obstruction & 3 & 876 & 15.0 & $4.33(1.04-18.16)$ \\
$\quad$ No emphysema & 5 & 333 & & Reference \\
$\quad$ Emphysema & & & 2.5 & $1.48(0.51-4.34)$ \\
$\quad$ Airway obstruction & 5 & 198 & 3.8 & \\
$\quad$ No emphysema & 10 & 267 & & \\
$\quad$ Emphysema & & & & \\
\hline
\end{tabular}

\section{Relationship Between Emphysema and the Risk of Lung Cancer}

On univariate analysis, the incidence density of lung cancer among individuals with and without emphysema on LDCT was 25.0 per 1,000 personyears and 7.5 per 1,000 person-years, respectively (RR, 3.33; $95 \%$ CI, 1.41 to 7.85 ; Table 2). Similarly, the incidence density of lung cancer in individuals with and without airway obstruction on spirometry was 32.3 per 1,000 person-years and 6.7 per 1,000 person-years, respectively $(\mathrm{RR}, 4.83 ; 95 \% \mathrm{CI}, 2.05$ to 11.41 ).

A potential synergy between emphysema detected on LDCT and airway obstruction detected on spirometry is suggested by the increased incidence density of lung cancer in subjects with both conditions (37.5 per 1,000 person-years) as compared to those with neither one (3.4 per 1,000 person-years; RR, 5.49; 95\% CI, 1.51 to 19.98). The incidence density of lung cancer in subjects with only one of the two abnormalities (emphysema or airway obstruction) was 18.8 per 1,000 person-years ( $R R, 10.94$; $95 \%$ CI, 3.01 to 39.74 ; Table 2).

In the stratified analysis, the presence of emphysema on LDCT was associated with an increased likelihood of a lung cancer diagnosis among subjects without airway obstruction (RR, 4.33; 95\% CI, 1.04 to 18.16). When the analysis was limited to participants with airway obstruction on spirometry, no relationship between emphysema on LDCT and lung cancer risk was found (RR, 1.48; 95\% CI, 0.51 to 4.34 ).

The results of the Poisson regression analyses are shown in Table 3. Emphysema detected on LDCT was significantly associated with a higher risk of lung cancer in a model adjusting for age, gender, and number of pack-years of smoking (RR, 3.13; 95\% CI, 1.32 to 7.44 ; model 1). Lung cancer was also more common among patients with airway obstruction after controlling for the same covariates (RR, 2.89; $95 \%$ CI, 1.14 to 7.27 ; model 2). However, in a final model (model 3) that included terms for presence of emphysema, airway obstruction, age, gender, and smoking history, emphysema (RR, 2.51; 95\% CI, 1.01 to 6.23$)$ and the number of pack-years of smoking (RR, 2.9; 95\% CI, 1.1 to 7.2) but not airway obstruction (RR, 2.10; 95\% CI, 0.79 to 5.58) were independently associated with a higher risk for lung cancer.

\section{Discussion}

Results of this prospective cohort study of current and former smokers suggest that the presence of

Table 3-Results of Multivariate Analysis*

\begin{tabular}{lcc}
\hline \hline \multicolumn{1}{c}{ Risk Factors } & RR & $95 \%$ CI \\
\hline Model 1 & & \\
$\quad$ Emphysema & 3.13 & $1.32-7.44$ \\
$\quad$ No emphysema & Reference & \\
Model 2 & & \\
$\quad$ Airway obstruction & 2.89 & $1.14-7.27$ \\
$\quad$ No airway obstruction & Reference & \\
Model 3 & & \\
Emphysema & 2.51 & $1.01-6.23$ \\
$\quad$ No emphysema & Reference & \\
Airway obstruction & 2.10 & $0.79-5.58$ \\
No airway obstruction & Reference & \\
\hline
\end{tabular}

*All models were adjusted for age, gender, and No. of pack-years of smoking. Pack-years of smoking was significantly associated with an increased risk of lung cancer in all three models. 
emphysema on LDCT is associated with an increased risk for lung cancer. Stratified and multivariate analyses showed that this association was significant even after controlling for the presence of airway obstruction on spirometry, suggesting that emphysema on LDCT is an independent risk factor for lung cancer. This information can help identify patients at high risk for lung cancer who may benefit from more-aggressive preventive interventions or lung cancer screening programs.

The majority of lung cancers occur in current or former smokers, and the risk increases with older age and longer exposure to tobacco. ${ }^{3}$ However, lung cancer develops in only a minority of smokers. Therefore, the identification of additional factors that may help in the selection of individuals with the highest risk may be useful. Many reports ${ }^{7}$ have linked abnormal airway function on pulmonary function testing with an increased risk for lung cancer. There is less information regarding the association between emphysema and lung cancer. ${ }^{15-17}$

Emphysema has traditionally been a pathologic diagnosis, but the development of CT-based image analysis techniques has lead to accurate noninvasive in vivo detection and quantification of emphysema. ${ }^{18}$ For example, CT has been shown to be useful in the selection of individuals with severe emphysema who are at a greater risk for a poor outcome after lung volume reduction surgery (ie, those with a homogenous distribution of emphysema). ${ }^{6}$ Moreover, quantification of emphysema using CT has been used to follow the effects of replacement therapy in patients with $\alpha_{1}$-antitrypsin deficiency. ${ }^{19,20}$ However, the clinical significance of emphysema on CT among individuals without symptoms or with normal pulmonary function tests remains unclear. A novelty of this study is the use of LDCT instead of high-resolution CT, as has been used in the aforementioned studies.

In this study, a strong association between emphysema detected on LDCT and lung cancer risk was found even among individuals with normal airway function. These results are consistent with previous retrospective and epidemiologic reports. ${ }^{15-17,21} \mathrm{Ad}-$ ditionally, a recent study ${ }^{22}$ has found that emphysema detected on CT, and not airway obstruction, was associated with a worse prognosis in smokers with early stage lung cancer. Conversely, a case-controlled study ${ }^{23}$ using data from subjects enrolled in the Mayo Clinic LDCT early lung cancer detection study found that severe airway obstruction, but not emphysema, was associated with a higher risk of lung cancer. The discrepancy in the results between this study and ours may be explained by several reasons. Firstly, the Mayo Clinic study follows a case-control design in which only a small subgroup of individuals of the entire cohort is used in the analysis. In our study, the entire population entered into the lung cancer screening trial was in- cluded in the analysis. Secondly, the proportion of subjects with airway obstruction that were included in the analysis was $67 \%$ and $79 \%$ in the control and lung cancer groups, respectively, in the Mayo Clinic study, and $25 \%$ in ours. Lastly, the method to determine the presence of emphysema was quantitative in the Mayo Clinic study and by visual assessment in ours. In the former, participants were subclassified into groups depending on the amount of emphysema; whereas in our study, only the presence or absence of emphysema was considered for the analysis.

The findings presented herein have several potential clinical implications. Lung cancer is the most lethal cancer in the world mainly due to the fact that $>80 \%$ of cases are diagnosed in advanced stages of the disease. In the last few years, a great interest in lung cancer screening research has emerged. A recent report by the International Early Lung Cancer Action Program consortium, ${ }^{11}$ among other studies, has shown promising results using annual LDCT. Other studies ${ }^{24}$ have found different results raising questions about mortality benefit, cost-effectiveness, and safety of lung cancer screening using LDCT. Several randomized control studies in the United States and in Europe are underway, and results should be available in a few years. If early detection of lung cancer with LDCT is shown to be effective by studies currently underway, the appropriate selection of the target population will be very important. For a screening program to be beneficial and cost-effective, it is necessary to identify individuals with the highest risk for lung cancer so that there is an adequate ratio of prevalence of the disease to the number of false-positive findings. The results presented herein suggest that emphysema detected on a baseline LDCT could be used in this context to identify individuals who may need additional followup studies. Conversely, individuals with no evidence of emphysema and with no suspicious nodules on a baseline LDCT may not require further screening. Additionally, LDCT screening may provide a means for diagnosing emphysema at an earlier stage, even before abnormalities develop that are detectable on pulmonary function testing. Whether the detection of emphysema in such early stages will have an impact on outcomes or on the natural history of the disease by earlier interventions is a question that should be explored in future studies. As an example, this information could be used to identify individuals who may need more-aggressive smoking cessation interventions. Smoking cessation has been shown to reduce the risk of lung cancer as well as to reduce the rate of progression of COPD. ${ }^{25,26}$

Several mechanisms have been proposed to explain the link between lung cancer and COPD. ${ }^{27}$ Firstly, both diseases share tobacco smoking as the 
most important etiologic factor. However, the majority of smokers remain disease-free throughout their lives, and only a few have airway obstruction, emphysema, and/or lung cancer. Smoke contains high concentrations of reactive oxygen species together with thousands of particles that are potentially carcinogenic and may induce inflammation in all smokers. ${ }^{28}$ However, it remains unclear why there are different responses to tobacco with some individuals having the hallmarks of cancer (uncontrolled cell proliferation, lack of cellular apoptosis, tissue invasion, and angiogenesis), others the hallmarks of COPD (increased apoptosis, matrix degeneration, ineffective tissue repair, inflammation, and lack of angiogenesis), while the majority remain disease free. ${ }^{27}$

A limitation of this study is the relatively small number of cancers diagnosed among the study participants. This is expected given the prospective design and the relatively low incidence of lung cancer even among high-risk smokers. However, the number of cases and the prevalence of emphysema and airway obstruction in the study population were sufficiently large to obtain positive findings even after using stratified analysis. Another potential limitation is that emphysema on LDCT was only determined qualitatively. However, it has been shown that qualitative assessment is a valid and reliable tool for the characterization of emphysema on CT. ${ }^{6}$ Furthermore, the prevalence of emphysema based on qualitative measurements in this study population is similar to what has been reported in other series of high-risk individuals. ${ }^{29}$ Lastly, we lacked complete information about current smoking status of some study participants. Thus, we were not able to adjust for the potential influence of smoking status (current vs former) on the risk of lung cancer in the multivariate analyses.

In summary, the results of this study suggest that emphysema detected on LDCT is an independent risk factor for lung cancer. If confirmed, this information can be used to select candidates for lung cancer screening or chemoprevention trials.

ACKNOWLEDGMENT: The authors thank Elena De Miguel, $\mathrm{RN}$, and Teresa Jiménez, RN, for performing the pulmonary function tests.

\section{REFERENCES}

1 Parkin DM, Bray F, Ferlay J, et al. Global cancer statistics, 2002. CA Cancer J Clin 2005; 55:74-108

2 Pirozynski M. 100 years of lung cancer. Respir Med 2006; 100:2073-2084

3 Hasan SU. ATS statement: cigarette smoking and health. Am J Respir Crit Care Med 1996; 154:1579-1580

4 American Thoracic Society. Standards for the diagnosis and care of patients with chronic obstructive pulmonary disease. Am J Respir Crit Care Med 1995; 152:S77-S121
5 Pauwels RA, Buist AS, Calverley PM, et al. Global strategy for the diagnosis, management, and prevention of chronic obstructive pulmonary disease: NHLBI/WHO Global Initiative for Chronic Obstructive Lung Disease (GOLD) workshop summary. Am J Respir Crit Care Med 2001; 163:1256-1276

6 National Emphysema Treatment Trial Research Group. Patients at high risk of death after lung-volume-reduction surgery. N Engl J Med 2001; 345:1075-1083

7 Tockman MS, Anthonisen NR, Wright EC, et al. Airways obstruction and the risk for lung cancer. Ann Intern Med 1987; 106:512-518

8 Bastarrika G, Garcia-Velloso MJ, Lozano MD, et al. Early lung cancer detection using spiral computed tomography and positron emission tomography. Am J Respir Crit Care Med 2005; 171:1378-1383

9 Henschke CI, McCauley DI, Yankelevitz DF, et al. Early Lung Cancer Action Project: overall design and findings from baseline screening. Lancet 1999; 354:99-105

10 Roca J, Burgos F, Sunyer J, et al. References values for forced spirometry: group of the European Community Respiratory Health Survey. Eur Respir J 1998; 11:1354-1362

11 Henschke CI, Yankelevitz DF, Libby DM, et al. Survival of patients with stage I lung cancer detected on CT screening. N Engl J Med 2006; 355:1763-1771

12 Maclure M, Willett WC. Misinterpretation and misuse of the к statistic. Am J Epidemiol 1987; 126:161-169

13 Kesley JL, Evan AS, Thompson WD. Methods in observational epidemiology. 2nd ed. New York, NY: Oxford University Press, 1996

14 Griner PF, Mayewski RJ, Mushlin AI, et al. Selection and interpretation of diagnostic tests and procedures. Ann Intern Med 1981; 94:557-592

15 Yang P, Schwartz AG, McAllister AE, et al. Lung cancer risk in families of nonsmoking probands: heterogeneity by age at diagnosis. Genet Epidemiol 1999; 17:253-273

16 Cassidy A, Myles JP, Liloglou T, et al. Defining high-risk individuals in a population-based molecular-epidemiological study of lung cancer. Int J Oncol 2006; 28:1295-1301

17 Mayne ST, Buenconsejo J, Janerich DT. Previous lung disease and risk of lung cancer among men and women nonsmokers. Am J Epidemiol 1999; 149:13-20

18 Stern EJ, Frank MS. CT of the lung in patients with pulmonary emphysema: diagnosis, quantification, and correlation with pathologic and physiologic findings. AJR Am J Roentgenol 1994; 162:791-798

19 Stolk J, Versteegh MI, Montenij LJ, et al. Densitometry for assessment of effect of lung volume reduction surgery for emphysema. Eur Respir J 2007; 29:1138-1143

20 Dowson LJ, Guest PJ, Stockley RA. Longitudinal changes in physiological, radiological, and health status measurements in $\alpha(1)$-antitrypsin deficiency and factors associated with decline. Am J Respir Crit Care Med 2001; 164:18051809

21 Turner MC, Chen Y, Krewski D, et al. COPD associated with lung cancer mortality in a prospective study of never smokers. Am J Respir Crit Care Med 2007; 176:285-290

22 Ueda K, Jinbo M, Li TS, et al. Computed tomographydiagnosed emphysema, not airway obstruction, is associated with the prognostic outcome of early-stage lung cancer. Clin Cancer Res 2006; 12:6730-6736

23 Kishi K, Gurney JW, Schroeder DR, et al. The correlation of emphysema or airway obstruction with the risk of lung cancer: a matched case-controlled study. Eur Respir J 2002; 19:10931098

24 Swensen SJ, Jett JR, Hartman TE, et al. CT screening for lung cancer: five-year prospective experience. Radiology 2005; 235:259-265 
25 Godtfredsen NS, Prescott E, Osler M. Effect of smoking reduction on lung cancer risk. JAMA 2005; 294:1505-1510

26 Anthonisen NR, Skeans MA, Wise RA, et al. The effects of a smoking cessation intervention on 14.5-year mortality: a randomized clinical trial. Ann Intern Med 2005; 142:233-239

27 Brody JS, Spira A. Chronic obstructive pulmonary disease, inflammation, and lung cancer. Proc Am Thorac Soc 2006; 3:535-538
28 Hecht SS. Tobacco carcinogens, their biomarkers and tobacco-induced cancer. Nat Rev Cancer 2003; 3:733-744

29 Omori H, Nakashima R, Otsuka N, et al. Emphysema detected by lung cancer screening with low-dose spiral CT: prevalence, and correlation with smoking habits and pulmonary function in Japanese male subjects. Respirology 2006; 11:205-210 


\section{Assessing the Relationship Between Lung Cancer Risk and Emphysema Detected on Low-Dose CT of the Chest}

Juan P. de Torres, Gorka Bastarrika, Juan P. Wisnivesky, Ana B. Alcaide, Arantza Campo, Luis M. Seijo, Jesús C. Pueyo, Alberto Villanueva, María D. Lozano, Usua Montes, Luis Montuenga and Javier J. Zulueta Chest 2007;132; 1932-1938

DOI 10.1378/chest.07-1490

\section{This information is current as of June 27, 2012}

\section{Updated Information \& Services}

Updated Information and services can be found at:

http://chestjournal.chestpubs.org/content/132/6/1932.full.html

\section{References}

This article cites 28 articles, 16 of which can be accessed free at:

http://chestjournal.chestpubs.org/content/132/6/1932.full.html\#ref-list-1

\section{Cited Bys}

This article has been cited by 33 HighWire-hosted articles:

http://chestjournal.chestpubs.org/content/132/6/1932.full.html\#related-urls

\section{Permissions \& Licensing}

Information about reproducing this article in parts (figures, tables) or in its entirety can be found online at:

http://www.chestpubs.org/site/misc/reprints.xhtml

\section{Reprints}

Information about ordering reprints can be found online:

http://www.chestpubs.org/site/misc/reprints.xhtml

\section{Citation Alerts}

Receive free e-mail alerts when new articles cite this article. To sign up, select the

"Services" link to the right of the online article.

\section{Images in PowerPoint format}

Figures that appear in CHEST articles can be downloaded for teaching purposes in PowerPoint slide format. See any online figure for directions.

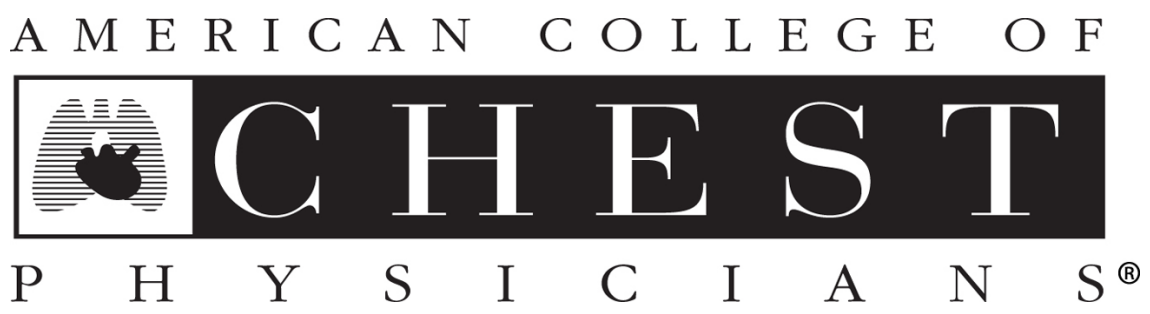

